\title{
Alfondeguilla, Fondeguilla
}

\author{
Recaredo Herrero Rodríguez
}

La Historia es muchas cosas, pero, entre otras, significa volver la vista al pasado para encontrar imágenes con las que identificarse, estructuras y episodios que nos reafirmen en lo que creemos que somos.

Manuel Ardit. Universidad de Valencia

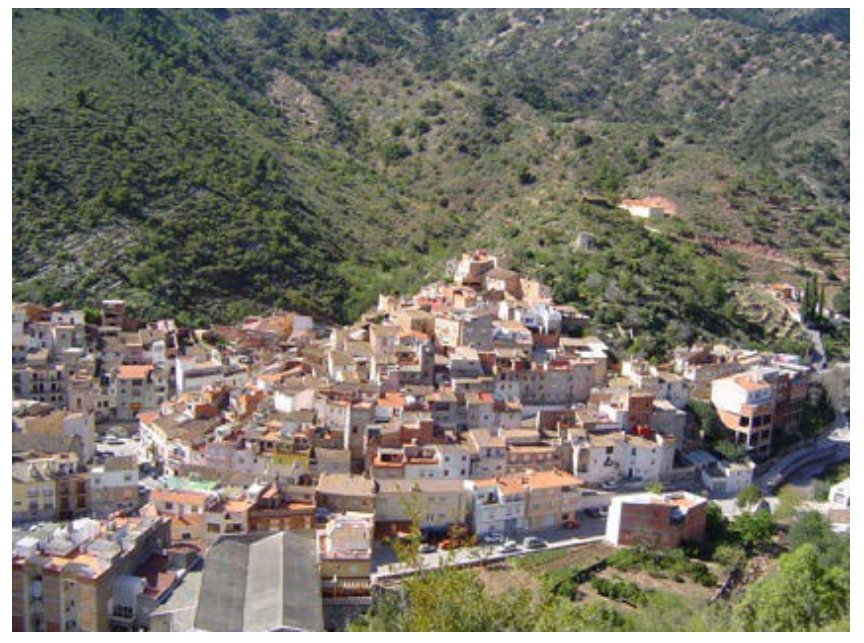

Figura 1. Vista del pueblo de Alfondeguilla

De los despoblados Castro y Beniçabdón quedan escasos restos. Del primero, unas construcciones que pudieran corresponder a una antigua mezquita y posterior iglesia dedicada a san Agustín. Es interesante el abastecimiento de agua, que se mantiene en la actualidad, trasportada desde un pequeño embalse, situado en el barranco Cabrera. A unos 3 kilómetros al norte se encuentra el castillo de Castro (figura 2), fortaleza inexpugnable que constituye una atalaya perfecta que domina la zona litoral desde Valencia hasta Castellón, especialmente el corredor de Borriol por donde trascurría la Vía Augusta, principal arteria romana que unía Gades con Roma, y la senda de la Palla que, desde Borriol, se dirigía al norte de Castellón hasta el Caminás. Algunos autores consideran que su origen pudiera ser púnico. 


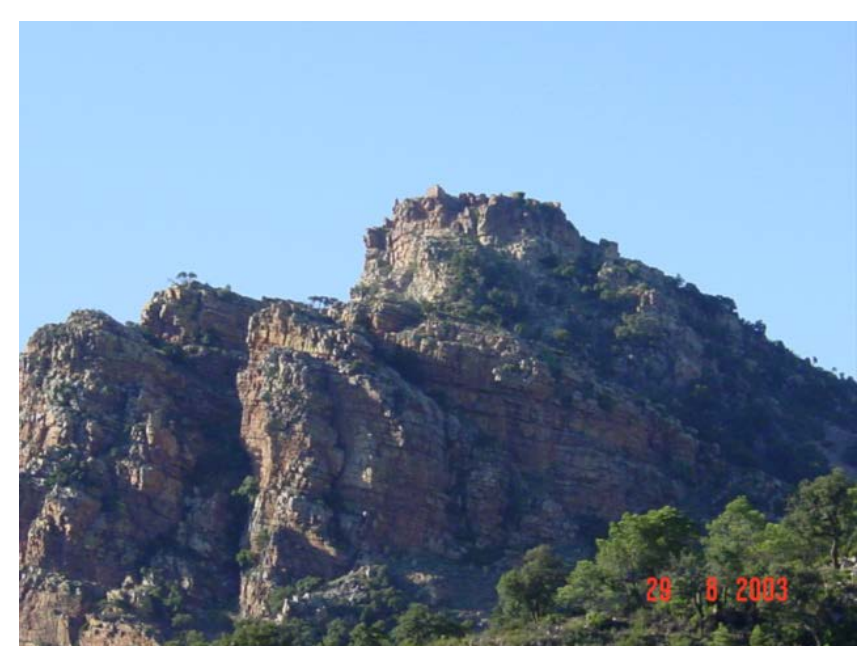

Figura 2. Castillo de Castro

\section{Etimología}

No hay unanimidad entre los estudiosos en cuanto al origen del nombre.

En el Llibre del Repartiment, según Quereda y Ortlells (1993):

En el Valle de Uxó, y en su parte más abrupta, poseía sus dominios el Castillo de Castro del que era sufragáneos, entre otros lugares, los habitantes de Al-fan-dech [...] El origen morisco de la villa parece atestiguarlo su nombre derivado, según unos del árabe Al-fondaq (Alfóndega, alhóndiga, posada).

Otro autor, Corominas, aunque considera el mismo origen lingüístico (posada), entiende que su etimología derivaría de Fondag-illha (hostal de Dios).

No falta quien, como Sarthou, estima que podía provenir de las muchas fuentes que existían cerca del asentamiento, de ahí Font de Guilla (fuente de la zorra).

Últimamente, es admitida y aceptada la opinión de la arabista Carmen Barceló, quien opina que el nombre deriva de Al-Khandag, cuyo significado (barranco) se adecua perfectamente con la topografía del valle.

Con independencia de su etimología, desde el siglo XIII, el topónimo Alfondeguilla/Fondeguilla ha registrado diferentes formas.

En la carta de Capitulació i nou establiment dels musulmans dels llocs de Castro i Alfondeguilla, que
Pere II de Aragón otorgó y firmó en la villa de Artana el 7 de abril de 1277, se dice:

En nom de Déu sia. Este privilege suficient mandólo obtener e facer por él, don Pedro, por la gracia de Dios rey d'Aragón. Otorgo a los moros de Castro e d'Alfandeguella que tornen a sus casas, e a laurar a lures tierras las sabidas... et qui's querra hir de Castro e d'Alfandaguella quan queran, onde querran, a tierra de moros, esto le-s otorgado de ninguna costa...

En los últimos párrafos del citado documento, aparece otra variante:

E si ha nengú moro fuydo en tiempo de guerra... o fora preso cautivo en aquella guerra, es tornará al loch de Castro o d'Alfondeguella...

En las cartas de población correspondientes a 1451, se repite el nombre de Alfandeguella (Peñarroja, 1984).

En el memorial que mosén Esteban Cardona dirige en 1611 al regente Fontanet, dice: «Señor: Los lugares de la Vall de Uxó son 9, a saber: Benisabdón, Castro, Fandeguella, Alcudia, Benigafull, Zeneja, Zeneta, Benisaat y Benigasló...».

Según el estudio de Eugenio Ciscar, referido a los pagos por el ganado trashumante, en los capbreves señoriales, conservados en el Archivo Ducal de Medinaceli, se encuentran informes detallados de las obligaciones de los vasallos en cuanto al pago de impuestos. En uno del siglo XVII, figura la siguiente anotación, referida a los lugares de la sierra de Eslida: «La Alfandiguilla también los de este lugar pagan al duque y sus sucesores los censos i diezmos en la forma dicha».

Por último, cuando se procedió a la reparación de una pequeña alquería, sita en las inmediaciones del pueblo, una de las tejas de la techumbre,

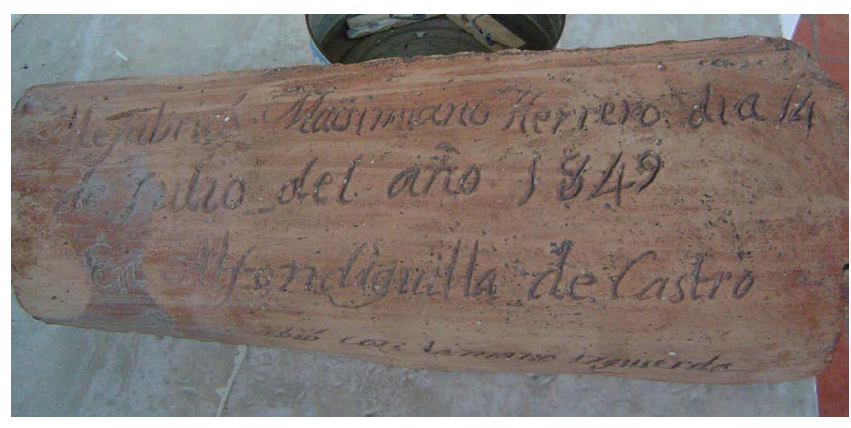

Figura 3. Teja de la alquería de 1849 
llevaba la siguiente inscripción: «La fabricó Maximiano Herrero, el día 14 de julio de 1849, en Alfondiguilla de Castro» (figura 3); se escribió con la mano izquierda.

\section{Prehistoria}

Volvamos la vista al pasado, como nos sugiere $\mathrm{M}$. Ardit. Pero, previamente, hemos de manifestar que la historia de Alfondeguilla no puede separarse de la de Uxó. Junto con Castro y Benisabdón, formó parte del valle hasta principios del xvir. Era como una avanzadilla en el interior de la sierra de los seis pueblos asentados en la costera que hoy forman el gran pueblo de La Vall d'Uixó.

Escasas han sido las prospecciones arqueológicas. En consecuencia, todo lo que hace referencia a la llegada y poblamiento del valle presenta dificultades aunque, por las razones indicadas de dependencia o apéndice de los cercanos asentamientos de Uxó, no será aventurado señalar algunos datos como probables, e incluso muy probables.

Investigaciones y prospecciones arqueológicas han puesto de manifiesto la presencia del hombre durante el paleolítico superior y el neolítico en zonas muy próximas a Alfondeguilla, como «las estaciones de Escales, Dehesa de Soneja o Can Ballester de Vall d'Uixó» (García Fuentes y Moraño) y los de Chovar, Eslida y Artana. Todos ellos forman un arco en cuyo centro, y a menos de media jornada, se encuentra Alfondeguilla. Esta situación central y equidistante de todos ellos la constituía como camino natural de entrada en la sierra en la que abundaba la caza. La existencia de cuevas o refugios naturales, amplios y resguardados, como la cueva de San Vicente, hacen que no resulte aventurado afirmar la presencia de grupos humanos en el territorio.

La hipótesis de asentamiento de forma esporádica o permanente durante la Edad del Bronce en el castillo de Castro, en base a los petrogrifos paralelos existentes en el interior del recinto, no puede descartarse teniendo en cuenta la posición estratégica del enclave.

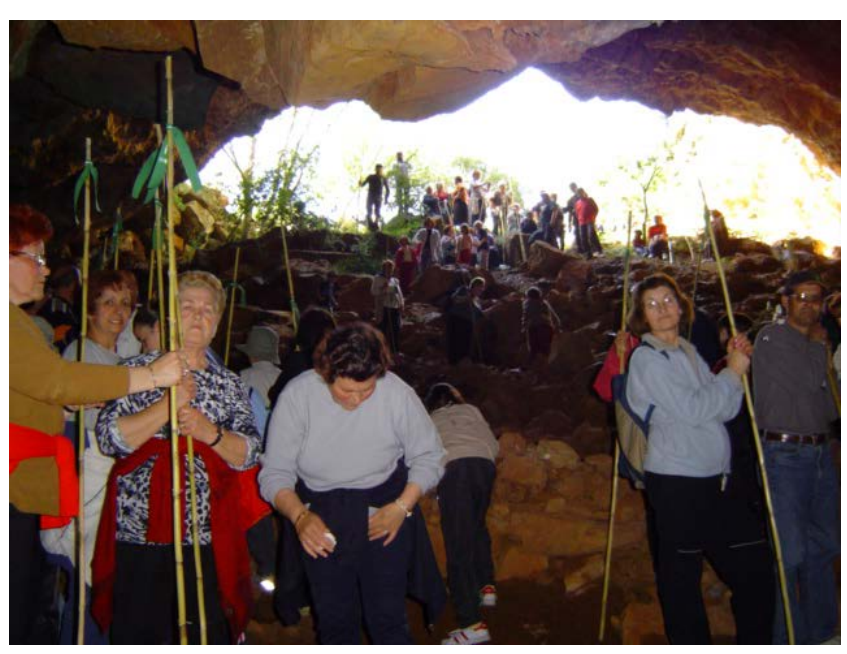

Figura 4. Cueva de San Vicente

\section{Iberos}

Entrados ya en épocas históricas, la presencia de poblados ibéricos en el territorio circundante es evidente. Y aquí, de nuevo, hemos de repetir lo anteriormente señalado a propósito de la relación con Uxó.

Los iberos que ocuparon el territorio, según Bosch Gimpera (1922), fueron los ilervacones y los edetanos. Para Honorio García (1962) «nuestro territorio pertenecía a la región de los edetanos».

Para Járrega (2011):

el poblamiento ibérico... responde en parte al típico emplazamiento de encastillamiento o de poblados en altura... Los poblados de mayores dimensiones tienen una dimensión media de 4 hectáreas habiéndose localizado dos: La Punta en Vall de Uxó y el Solaig en Betxí. Seguidamente aparecen poblados de dimensiones medianas como... San Josep de Vall de Uxó...

El promontorio donde posteriormente se asentaron las poblaciones árabes de forma permanente, el el Piló y Castro, reúnen condiciones parecidas al poblado de San Josep: zonas de fácil aguada y control del espacio físico circundante. No es descartable la hipótesis de presencia ibera en nuestro pueblo, si bien la proximidad de San Josep (3 kilómetros) podría significar la no necesidad de otro $u$ otros poblados. 


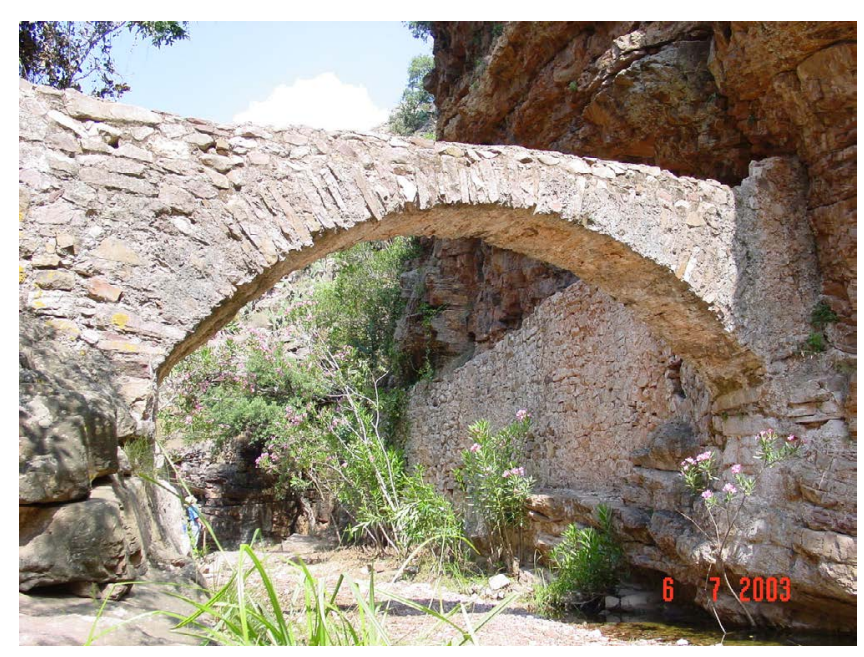

Figura 5. Arco romano. Arquet

\section{Romanización}

A finales el s. III a. de C., Roma inicia la conquista de Hispania que se prolongará hasta el año 19 a. de C.

La existencia de numerosos asentamientos y villas en Uxó y pueblos circundantes (El Pinar y Corralets en Artana; barrio de l'Alcudia, camí de Cabres, camí de Clotxes, Font del Canyet, Pla d'Odell, Horta Seca, en La Vall d'Uixó; l'Alquería y Rajadell, en Moncofa; la Font Calda, Santa Bárbara, el Secante, en Vila-Vella, etc.), nos lleva a considerar la posibilidad no de villae en el sentido de «centro agrario de cierta envergadura que tenía por finalidad la producción de excedentes» (Jàrrega, 2011), pero sí explotaciones menores dependientes de las villae de La Vall d'Uixó.

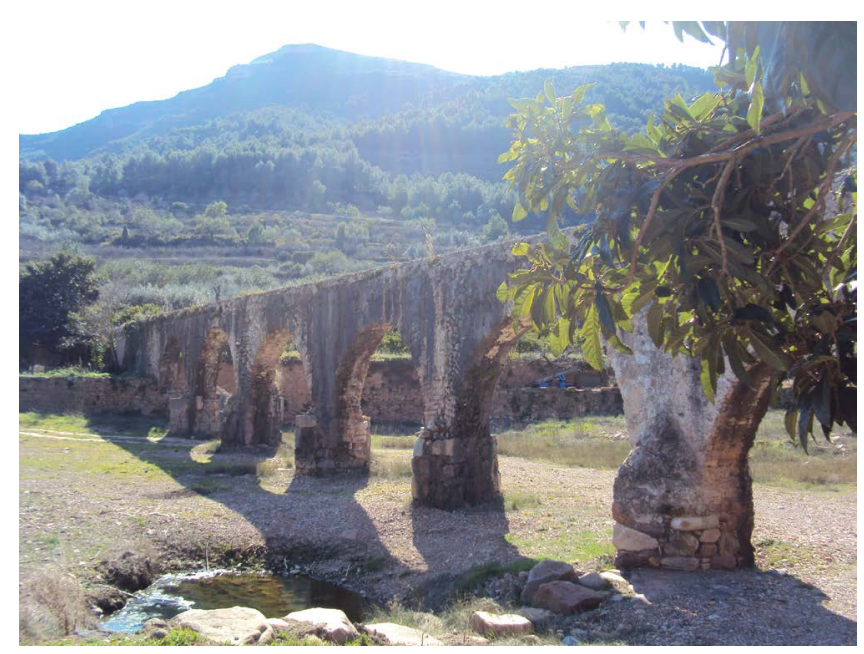

Figura 5. Acueducto. Pont de l'aigua

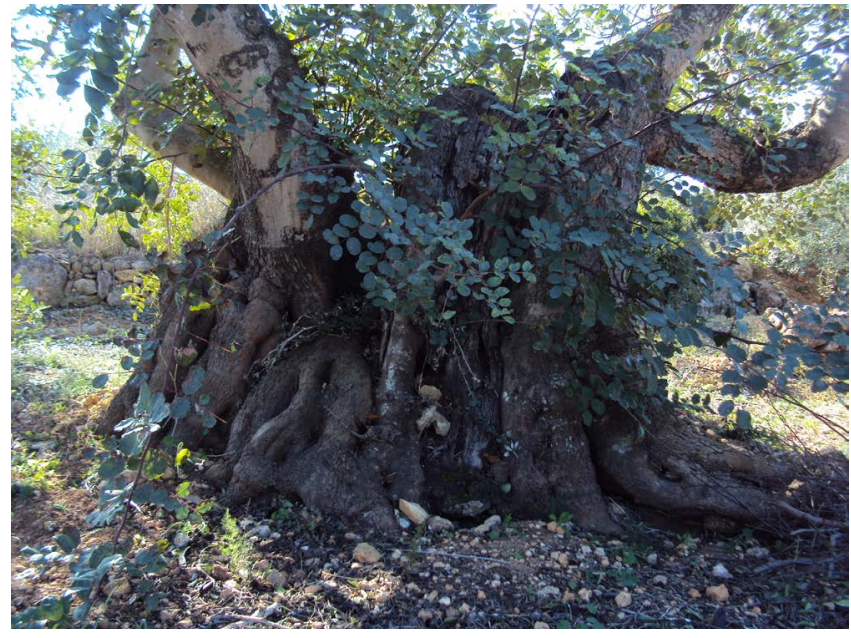

Figura 6. Algarrobo centenario

La existencia del Arquet, pequeño acueducto que permitía pasar una conducción de agua de la margen izquierda a la derecha del río Belcaire hasta llegar a un pequeño molino situado a pocos centenares de metros aguas abajo, avalaría la hipótesis de presencia romana en nuestro pueblo. Tanto el Arquet como el Molinet son, sin lugar a dudas, romanos (figura 5), lo que supone la existencia de una explotación agraria y una pequeña industria.

\section{Los árabes}

A principios del s. viII (711), los árabes, al mando de Tarik, cruzan el estrecho. Se inicia así la conquista de la Península. No encontraron excesiva resistencia y, en poco más de 20 años, todo el territorio, excepto parte de la cornisa cantábrica, es absorbido.

Nuestra zona, el valle de Uxó, fue conquistada por el hijo de Muza, Abdel-Aziz, en 714. El contacto con la población autóctona fue relativamente pacífica (García de Cortázar 1973), fruto de capitulaciones y pactos...

cuyo resultado fue siempre el sometimiento de los hispanogodos... facilitando y favoreciendo la permanencia de los antiguos habitantes en sus tierras y ocupaciones... pudiendo conservar una serie de garantías personales y religiosas con tal que satisficieran un tributo y se mantuvieran sumisos a la autoridad de los dominadores árabes y bereberes.

No parece que la ocupación de estas tierras se realizara masivamente. El número de los invasores era 


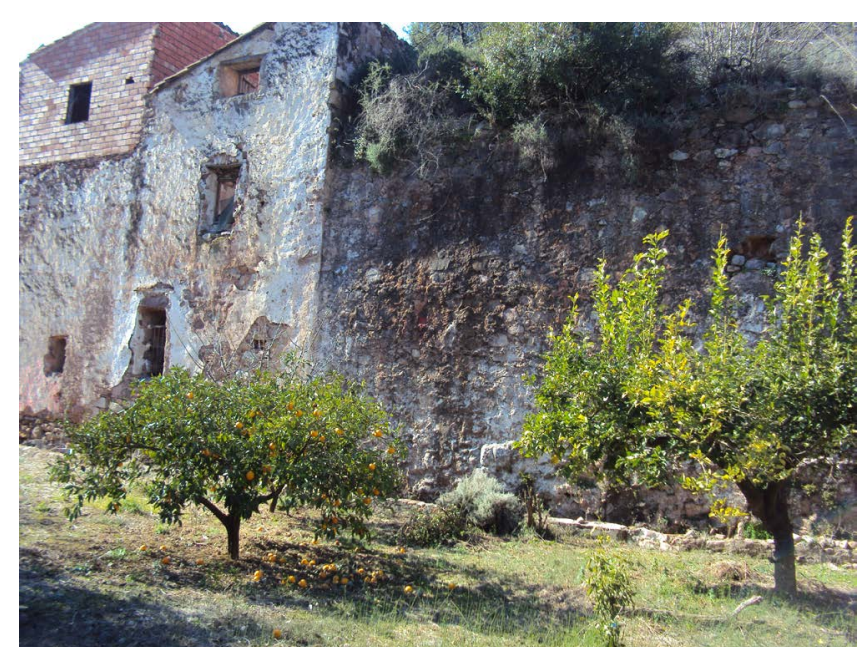

Figura 8. Molino

bastante pequeño. En opinión de Honorio García (1962):

La tribu yemenita de Beni-Gasló y las bereberes de los Zebnetes y Beni-Said, algo más al interior del valle y, ya en el fondo, las de Bai-Gafull y Beni-Capdó, serían las primeras.

Probablemente, esta última sería la iniciadora de los poblados del valle de Alfondeguilla.

De la vida y costumbres de los habitantes de nuestro pueblo, durante los cuatrocientos años que median desde la conquista de Abdel-Aziz hasta la llegada de Jaime I, poco sabemos. Desde el punto de vista económico, no pasaría de ser una vida de subsistencia: el inicio del abancalamiento de los montes, la domesticación del agua y los olivos y algarrobos que aún perduran y que fueron plantados en aquellas épocas (figura 7). Cereales, higos, vino,

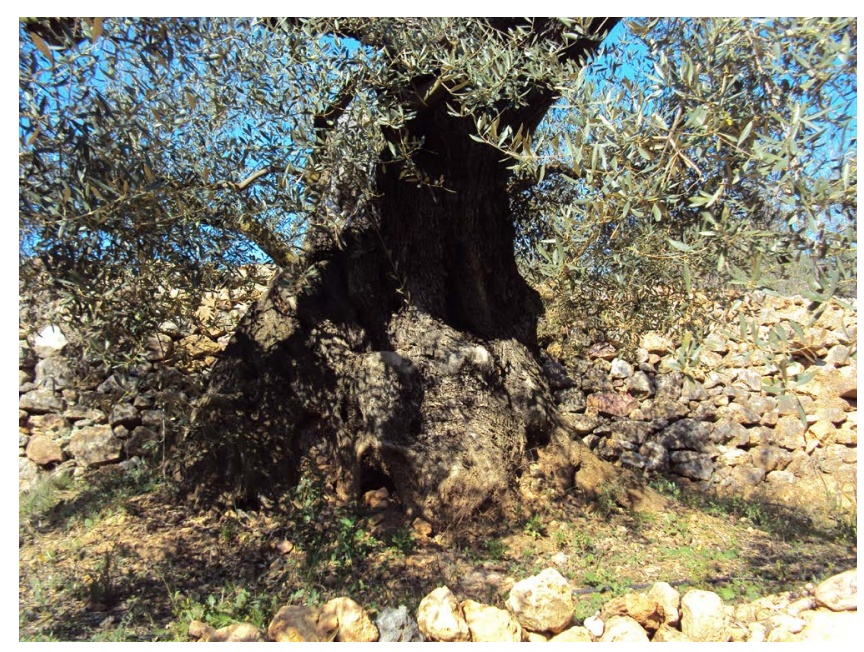

Figura 9. Olivo milenario pasas, aceite y algarrobas constituían la base de la agricultura y, como consecuencia, de la pequeña industria derivada de estos productos, siendo de destacar los molinos (figura 8).

Gran importancia debió tener la ganadería, especialmente la ovina y caprina. En el LLibre dels Fets, cuando habla «de la rendició de Castre» dice: «...i hi ferem els tractes per una quantitat d'ovelles i de cabres...». No determina el número de cabezas que les fue entregado a los de Castro; sin embargo, cuando los de Uxó rinden su castillo, al día siguiente del de Castro, concreta el número tanto de ganado menor como mayor: «I els donàrem ovilles i cabres fins a mil-cin-centes, i seixanta avaques... i els donàrem tres rossins...», cantidad importante, mucho mayor, sin duda, que la que entregó a los de Castro, pero que indica la importancia de la cabaña existente. En la carta pobla de La Vall d'Uixó, establece:

E que hajen tots lurs termes o lurs bestiars, de Uxó, e Nules, e Almenara, e lo terme de Urmell en la Plana, e les vinyes de la alqueria de Carç e Alfàndech, segons que ja eren deputats a ells en tems de moros. E que pusqua anar lo lur bestiar en tot lo terme de Xova, segons que a ells era ja legut.

La documentación relativa a la trashumancia (sentencias, pactos, privilegios y acuerdos) entre las aldeas de Teruel y la sierra de Espadán es extensa. Conocemos los itinerarios, especialmente los que, desde Barracas, se dirigían a La Vall d’Uixó, pasando por Jérica y Segorbe que integraba los cordeles de Castelnovo, pista de Chovar, rambla de Azuebar, Alfondeguilla, Eslida, Ain, Alcudia, Onda, etc. En 1329 se concedió a los vecinos de Onda el derecho de llevar sus ganados a San Agustín y otras aldeas de Teruel.

En las cartas de población de los primeros años del siglo XVII, tras la expulsión de los moriscos, se aportan noticias sobre el tema ganadero. Y, así, en la carta fechada en 28 de junio de 1613, en Alfondeguilla, se otorga a los pobladores el derecho de pastos y el usufructo de la carnicería por ocho años. Se aclara además que, pasado ese plazo, se concederá a los vecinos un bovalar:

...otro si ha sido tratado y capitulado entre dichas partes que el dicho Juan Saens de San Martín, en 


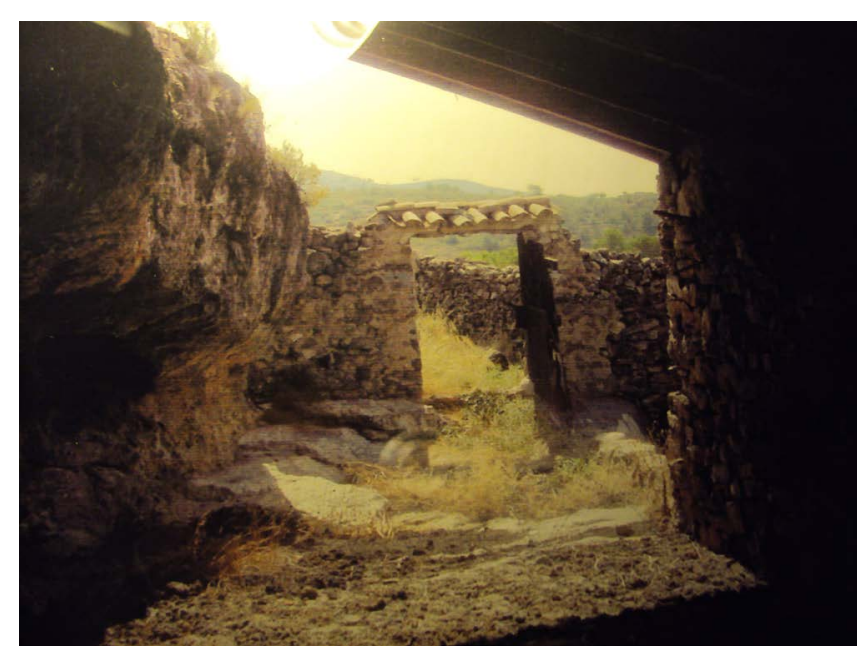

Figura 9. Paridera

dicho nombre, da a los vecinos vasallos las hiervas de los términos de dichos lugares de Castro y Alfondeguilla, es a saber, para que puedan pacentar sus ganados propios, así de casar como de serda y cabreo, con que hayan de pagar a su Excelencia y sus sucesores, según que con el presente capítulo se obligan, la décima parte de los corderos y cabritos y marranchones que criaren, es a saber, de diez uno...

El gran número de corrales o parideras existentes en el termino del pueblo, bien aprovechando cuevas naturales o de construcción nueva, atestiguan la importancia de la ganadería en el territorio desde tiempo inmemorial (figura 10).

Desde el punto de vista religioso, la falta de un cristianismo arraigado profundamente permitió una islamización lenta, pero inexorable, de la población de tal manera que, a la llegada de las huestes de Jaime I, la población sería musulmana.

\section{La Reconquista}

Habiendo tomado Les Malloques en 1230, persuadido por Hugo de Folcalquier, maestre del hospital, y por don Blasco de Aragón, decide la conquista de Valencia. Al siguiente año, desde Teruel, siguiendo el valle del Palencia, se dirige a la Plana para tomar Burriana, paso indispensable para llegar a Valencia. En 1233, tras un prolongado asedio, fue tomada Burriana.

En la cuaresma de 1238, toma Almenara y recibe (Llibre dels Fets) «missatge d'Uixó, de Nules e de Castre, dient que, si voliem fer bè, ens rendirien els castells, ja que teníem Almenara». El rey no cita a todos a la vez «perque no voliem que l'un sabera els tractes de l'altre».

El Llibre del Fets relata con todo detalle la estrategia llevada a cabo por Jaime I que quería pactar con cada uno de los representantes por separado. Primero, a los de Castre, probablemente por ser los más débiles:

I manarem als de Castre que s'hi quedaren amb nos, i que fariem els seus tractes; i hi ferem els tractes per una quantitat dovelles i cabres, i donant vestits a cin vells i donan-los dues cavalcadures. I els reconeguerem la seu llei i les seues franqueses, així com en el seu temps ho solien tenir els serraïns; i els donerem cinc escuders nostres a cavall per tal que ells anarem protegits, i deu homes de peu.

Los pactos, seguramente, fueron incumplidos en todo o en parte, lo que ocasionó que buena parte de los pueblos y castillos se levantaran contra las huestes de Jaime I. La sierra de Espadán fue refugio de los sublevados. La reacción del rey fue expulsar a los sublevados «Después d'exposar els danys i les injuries que ens han fet, direm publicament, devant de tots, que jo vull repoblar de cristians la terra». Hay constancia de la llegada de familias al valle de Uxó a quien el rey reparte casas y tierras.

Que Castre y Alfandaguella participaron en este levantamiento no admite dudas, porque el 7 de abril de 1277, en Artana, el rey Pere, hijo de Jaime I, otorga Carta de Capitulació i nou Establiment a los moros de ambos lugares (AV-UjI, 2007).

En nom de Dèu sia.

Este privilege sufficient mandólo obtener e facer por él, don Pedro, por la gracia de Dios rei d'Aragón.

Otorgo a los moros de Castro e d'Alfandaguella que tornen a sus casas, e a laurar lures tierras las sabidas Perdonámosles toda errada que hayan feita en la guerra atadora. E lixámoslos en la suya Çuna, e en la suya Xara e en sus matrimonios; e abeçar sus fillos en su Alcorán; e que haien erençia nos a otros en muert...

E que los suelta que puedan comprar trigo en $\mathrm{Bu}$ rriana, pora simient en lures tierras.

E que nos den el huyteno de todas cullidas, salvant de las figas ni de las garrofas, ni de las uvas de las parras, ni de la ortaliça; sino la que vendrá de la ortaliça, que paguen por ella. 
E sémoles francos de la gallinas e de los huevos, e que nos den del bestiar e de las colmenas, de $\mathrm{XL}^{\mathrm{a}}$ que dé una...

E si ha ningún moro fuydo en tiempo de la guerra, de Alfandaguella o de Castro, o fora preso cativo en aquella guerra, es tornara al loch de Castro o d'Alfandaguella, que sea forro.

E confirmámoles todo lo que diç nostro padre, Dios li perdone.
En 1354, Pere el Ceremoniós confirmó en todos sus términos la Carta.

\section{Referencias}

AV-UJI. Archiu Virtual de la Universitat Jaume I (2007). Cartes pobles de les comarques de Castelló. http://www. jaumeprimer.uji.es/cgi-bin/noticia.php?referencia=13052007 21/07/2013

Balbás, J. A. (1892). El libro de la provincia de Castellón. Caja de ahorros de Castellón. Castellón.

Bosch Gimpera, Pedro (1922). Fontes Hispaniae Antiquae de Adolf Schuten. Universidad de Barcelona.

Fuster i Ortells, Joan (1998). Poetes, moriscos i Capellans. Tres i Quatre. Valencia.

García de Cortázar, José Ángel (1973). Historia de España: Época medieval, vol. 2. Alizanza Madrid.

García y García, Honorio (1962). Notas para la historia de la Vall d’Uxó. Excmo. Ayuntamiento e Institutio laboral de Vall d’Uxó. Castellón.

García Fuertes, J. M. y Moraño Poblador, I. (2005). Alfondeguilla: avance preliminar sobre su contexto arqueológico. Ayuntamiento de Alfondeguilla. Castellón.

Járrega, Ramón (2011). La Plana romana. Diputación provincial de Castellón. Castellón.

Pardo Molero, Julián Francisco (1992). La rebelión del islam, Sierra de Espadán 1526. Revista de historia moderna. 18.

Peñarroja Torrejón, Leopoldo (2007). Cristianismo Valenciano. De los Orígenes al s. XIII. Romeu-Ajuntament de Valencia. Valencia.

Peñarroja Terrejón, Leopoldo (1984). Moriscos y repobladores en el Reino de Valencia: La Vall d’Uixó 1525-1625. Cartoné Editorial. Valencia

Quereda Sala y Ortells Chabrera (1993). La Plana de Castellón, estudio geográfico. Diputación provincial de Castellón. Castellón. 